\title{
POWER FACTOR CORRECTION OF 6.6KV DISTRIBUTION LINE IN LC11 RMHS DEPARTMENT, JSW STEEL
}

\author{
Nandish B M' M Gopalakrishna $^{2}$, Jiby C Jose ${ }^{3}$ \\ ${ }^{1}$ PG Student, Department of EEE, U.B.D.T.C.E, Karnataka, India \\ ${ }^{2}$ Associate Professor, Department of EEE, U.B.D.T.C.E, Karnataka, India \\ ${ }^{3}$ Deputy Manager, RMHS Department, JSW Steel Ltd., Karnataka, India
}

\begin{abstract}
This paper discusses the design, implementation and analysis of a three phase $(6.6 \mathrm{kV}, 50 \mathrm{~Hz})$ capacitor bank controller unit. Power factor correction using capacitor banks reduces reactive power consumption which will lead to minimization of losses and at the same time increases the electrical system's efficiency. Most of the industrial installations have large electrical loads which are inductive in nature, which results in a lagging power factor. Power factor is the value of a system that reflects how much power is being borrowed from the power company for the system. Many power companies regulate industrial power factors to make sure that they do not fall below a certain level and charge the customer more on their utility bills if the power factor falls below a certain level. Power factor correction serves to correct low power factors by reducing the phase difference between the current and voltage at the distribution point for a company. In case of rapidly varying and scattered load it becomes difficult to maintain a high power factor by manually switching on/off capacitors in proportion to variation of load. Current transformer is used to measure the load current for sampling purposes. The most common way to correct the power factor is to switch capacitor banks at the source to generate reactive power. This work is to make a system that will switch capacitor banks when the power factor drops below a certain point to avoid power company charges.PLC is used to control of switching on/off capacitor bank to improve power factor.
\end{abstract}

Keywords: Power Factor, Reactive power, PLC

\section{INTRODUCTION}

During recent years, increasing attention has been paid to minimize the energy cost and inefficiency in electricity generation, transmission and distribution [1]. In electrical plants (Here JSW Steel Ltd.) the loads draw from the network electric power (active) as power supply source or convert it into another form of energy or into mechanical output (e.g. electrical motors). To get this, it is often necessary that the load exchanges with the network (with net null consumption) the reactive energy, mainly of inductive type. This energy, even if not immediately converted into other forms, contributes to increase the total power flowing through in the electrical network, from the generators, all along the conductors, to the users. To smooth such effect, the power factor correction of the electrical plants is carried out. The power factor correction obtained by using capacitor banks to generate locally the reactive power necessary for the transfer of electrical useful power, allows a better and more rational technical-economical management of the plants. When designing a compensation scheme, one should attempt to achieve the most economical solution in which the saving achieved in the equipment cost is significantly greater than the procurement cost of the reactive power.
Different systems are available to produce reactive energy and improve the power factor. Particularly, shunt capacitors at the nearest point to the loads is a well established approach to improve the power factor. Shunt capacitors are attractive because they are economical and easy to maintain. Not only that, but also they have no moving parts, unlike some other devices used for the same purpose [6]. When the current is phase shifted, it takes more current to deliver the same amount of active power.

Reactive power is not used to do work, but is needed to operate equipment [5]. Many industrial loads are inductive such as motors, transformers, etc. The current drawn by an Inductive load consists of magnetization current and power producing current. The magnetizing current is required to sustain the electro-magnetic field in a device and creates reactive power. An inductive load draws current that lags the voltage, in that the current follows the voltage wave form. The amount of lag is the electrical displacement (or phase) angel between the voltage and current. Low power factor is usually not that much of a problem in residential homes. It does however become a problem in industry where multiple large motors are used. So there is a requirement to correct the power factor in industries. Generally the power factor correction capacitors are used to correct this problem. 


\subsection{Source/ Cause of Low Power Factor}

1) Induction motors

2) Transformer

3) Arc furnace

4) EM ballast

5) Arc welders

6) Alternator

7) Magnetic levitation

8) Rewound motors may reduce the pf due to increase in airgap, change the materials and size of conductors etc.

9) Induction heating

10) HPMV/HPSV Lamps

11) Over rating of equipments: if the induction motor is oversized, than power factor is reduced because it runs at lower load than rated load.

12) Increase in system voltage: during off-peak period the load is decreased but system voltage is increased. Hence due to this high voltage, magnetizing current in transformer, induction motor etc increase which leads to increase the KVAR and power factor is reduced [2].

\subsection{Technical Advantages of Power Factor Correction}

As previously mentioned, by correcting the power factor of an installation supplying locally the necessary reactive power, at the same level of required output power, it is possible to reduce the current value and consequently the total power absorbed on the load side; this implies numerous advantages, among which a better utilization of electrical machines and of electrical lines [2].

The main advantages of power factor correction can be summarized as follows:

- Power factor correction allows to obtain advantages also for cable sizing.

- By improving the power factor of the installation, these machines can be sized for a lower apparent power, but still deliver the same active power.

- By improving the power factor, a reduction of power losses is obtained in all the parts of the installation upstream the point where the power factor has been improved.

- Reduction of voltage drops.

\section{TYPES OF POWER FACTOR CORRECTION}

(PF)

- Distributed PF correction

- Group PF correction

- Centralized PF correction

- Combined PF correction

- Automatic PF correction

\subsection{Proposed Method}

\subsubsection{Centralized Power Factor Correction}

The profile of loads connected during the day has a primary importance for the choice of the most convenient type of power factor correction. For installations with many loads, where not all the loads function simultaneously and/or some loads are connected for just a few hours a day, it is evident that the solution of distributed power factor correction becomes too onerous since many of the installed capacitors stay idle for a long time [3]. Therefore the use of one compensation system only located at the origin of the installation allows a remarkable reduction of the total power of the installed capacitors.

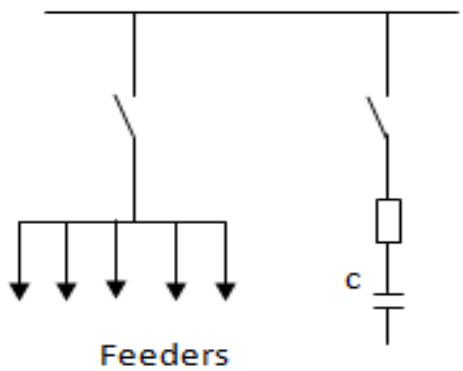

Fig 1

In centralized power factor correction automatic assemblies are normally used (see above automatic power factor correction Fig no 1) with banks divided into steps, installed directly in the main distribution boards; the use of a permanently connected bank is possible only if the absorption of reactive energy is quite constant all day long. The centralized solution allows an optimization of the costs of the capacitor bank, but presents the disadvantage that the distribution lines on the load side of the power factor correction device shall be sized keeping into account the full reactive power absorbed by the loads [3].

\section{PRESENT SYSTEM}

Present system is operating with 58 feeders supplied by 2 incoming lines of $6.6 \mathrm{kv}$ each. Incoming line 1 and line 2 are operating at a total load of $14.063 \mathrm{Mw}$ and $12.15 \mathrm{Mw}$ respectively at a power factor of 0.7 [4].

\subsection{Modification Suggested}

Since the operating power factor of lines 1 and 2 are low, there is need to provide compensation. The compensation proposed here is static capacitor banks with centralized power factor method. Modified system block diagram is shown below in figure 2. 


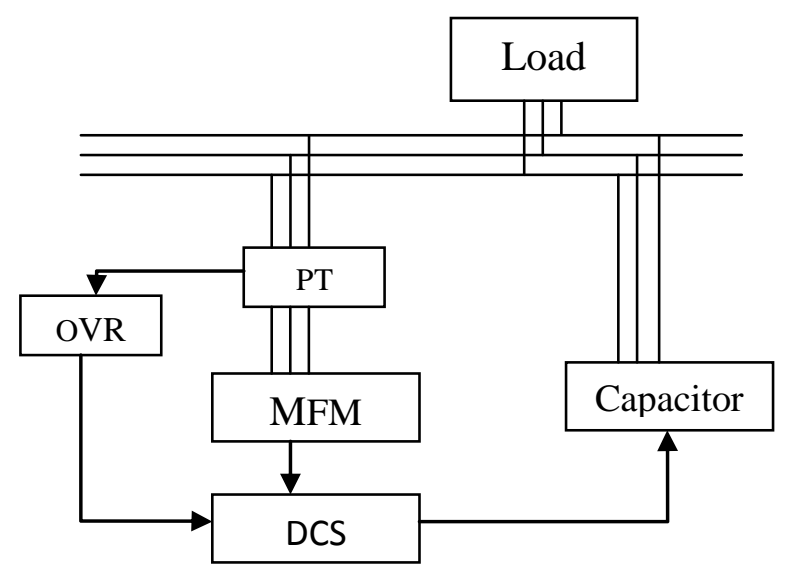

Fig-2: Suggested system block diagram

\section{DESIGN}

Some considerations were made while designing the capacitor banks, those considerations are as follows:

1. Harmonics introduced due to the inductive equipments are not considered while designing the capacitor banks.

2. Care should be taken such that design value of capacitor should not cause the bus voltage to exceed $5 \%$ of the rated voltage.

\subsection{Calculation}

\subsubsection{Incomer 1}

Total load $=20.09 \mathrm{Mva}$

$\mathrm{P}=14.063 \mathrm{Mw}$

Present P.F $=0.7$

Required P.F $=0.95$

$\operatorname{Cos} \varphi 1=0.7$

$\operatorname{Cos} \omega 2=0.95$

$\mathrm{Q}_{\mathrm{c} 1}=\mathrm{P}(\tan \varphi 1-\tan \omega 2)$

$\mathrm{Q}_{\mathrm{c} 2}=\mathrm{Q}_{\mathrm{c} 1} *(7.2 / 6.6)$

Reactance of capacitor $=X_{c}$

Required reactance of reactor $\left(\mathrm{X}_{\mathrm{l}}\right)=\mathrm{X}_{\mathrm{c}} * \mathrm{P}$

$$
\mathrm{X}_{\text {total }}=\mathrm{X}_{\mathrm{c}}-\mathrm{X}_{1}
$$

Resulting P.F current $(\mathrm{I})=\mathrm{V}_{\mathrm{l}-\mathrm{l}} /\left(\mathrm{X}_{\text {total }} * \sqrt{3}\right)$

Resulting reactive power, $\mathrm{Qc}=\mathrm{V}_{\mathrm{l}-\mathrm{I}} * \mathrm{I} * \sqrt{3}$

For star connection:

$$
\begin{gathered}
\mathrm{C}=\mathrm{Qc} /\left(7200^{2} * 2 * \mathrm{f} * \pi\right) \\
\mathrm{C}=776.74 \mu \mathrm{F}
\end{gathered}
$$

\subsubsection{Incomer 2}

Total load $=17.35 \mathrm{Kva}$

$\mathrm{P}=12.145 \mathrm{Mw}$

$\mathrm{P} . \mathrm{F}=0.7$

step $=0.05$

$\operatorname{Cos} \omega 1=0.7$

$\operatorname{Cos} \omega 2=0.75$

$\mathrm{Q}_{\mathrm{c} 1}=\mathrm{P}(\tan \omega 1-\tan \omega 2)$

$\mathrm{Q}_{\mathrm{c} 2}=\mathrm{Q}_{\mathrm{c} 1} *(7.2 / 6.6)$

Reactance of capacitor $=X_{c}$

Required reactance of reactor $\left(\mathrm{X}_{1}\right)=\mathrm{X}_{\mathrm{c}} * \mathrm{P}$

$$
\mathrm{X}_{\mathrm{total}}=\mathrm{X}_{\mathrm{c}}-\mathrm{X}_{1}
$$

Resulting P.F current $(\mathrm{I})=\mathrm{V}_{\mathrm{l}-1} /\left(\mathrm{X}_{\text {total }} * \sqrt{3}\right)$

Resulting reactive power, $\mathrm{Qc}=\mathrm{V}_{\mathrm{l}-1} * \mathrm{I} * \sqrt{3}$

For star connection:

$$
\begin{gathered}
\mathrm{C}=\mathrm{Qc} /\left(7200^{2} * 2 * \mathrm{f} * \pi\right) \\
\mathrm{C}=666.82 \mu \mathrm{F}
\end{gathered}
$$

\section{RETURN ON INVESTMENT (ROI):}

Total power consumption in the year 2013 at power factor of 0.7 is $45162 \mathrm{Mw}$. Cost per unit is $5.00 \mathrm{Rs}$. Hence the total cost for $45162 \mathrm{Mw}$ is:

Total cost $=45162000 * 5.00$

$$
=22,58,10,000 \mathrm{Rs}
$$

If the power factor is improved from 0.7 to 0.95 the total power consumption can be calculated as:

Power consumption at 0.95 P.F

$$
\begin{gathered}
=(45162 * 0.7) / 0.95 \\
=33277.26 \mathrm{Mw}
\end{gathered}
$$

Therefore cost for 33277.26 Mw of power

$$
\begin{gathered}
=33277260 * 5.00 \\
=16,63,86,300 \mathrm{Rs}
\end{gathered}
$$

Hence savings $=225810000-166386300$

$$
=5,94,23,700 \mathrm{Rs}
$$

\section{RESULTS}

Suitable capacitor banks are designed in order to improve the present system power factor from 0.7 to 0.95 for both the incomers. For incomer 1 each capacitor with a value of 776.74 
$\mu \mathrm{f}$ is used in the capacitor banks. For incomer 2 each capacitor with a capacitor value of $613.73 \mu \mathrm{F}$

Value of each capacitor related with the incremental power factor are shown in graph below
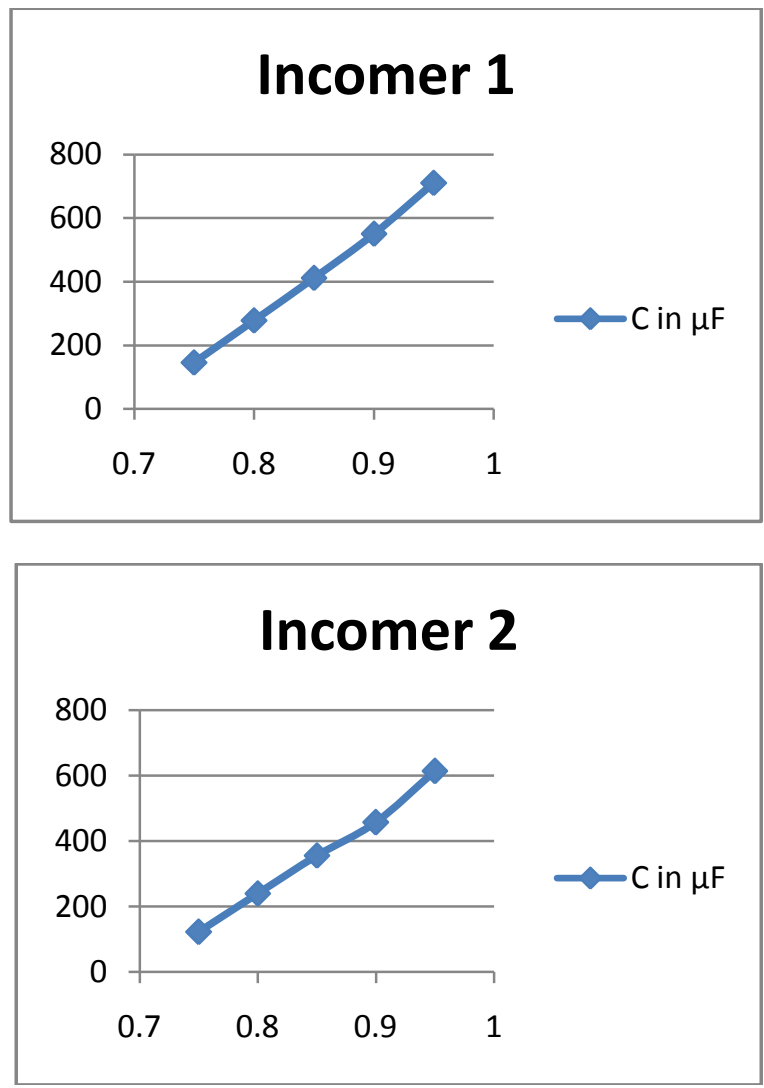

\section{CONCLUSIONS}

The most economical way of producing reactive power required by most electrical devices is by the use of capacitors. Capacitors reduce network losses and voltage drop and the transmission of reactive power is avoided. This means considerable annual savings.

If the bus voltage exceeds $5 \%$ of the rated voltage, over voltage relay sends signal to the PLC such that the capacitor banks are disconnected from the line to prevent the system damage.

\section{REFERENCES}

[1] Mohamed A. EL-HADIDY, Samir A. EZZ EL-ARAB, Dalal H. HELMI, \& Mohamed T. IBRAHIM "The Impact Of Capacitor Bank Installation On The Performance Of Distribution Systems" A Case Study CIRED. May 2007

[2] Kashyap L. Mokariya, MihirRaval, Patel SnehalS."Automatic Power Factor Controller Using Programmable Logic Controller (PIc)”. 2013 IJEA
[3] Technical application papers NO.8 "Power Factor Correction and Harmonic Filtering in Electrical Plants" render ABB.

[4] User Manual LC11 Panel Board, RMHS Department, JSW Steel.Ltd

[5] T. Miller - "Reactive Power Control In Electric Systems" | John Wiley \& Sons. 1982

[6] RamasamyNatarjan - "Power SystemCapacitors" Taylor \& Francis. 2005 